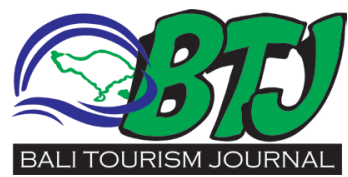

\title{
A Report Trip from Odaesan National Park \& Woljeongsa Temple
}

\author{
Musa Kothar Uropmabin
}

*Participant of Indonesia-Korea Youth Exchange Program (IKYEP) 2014; yumip2013@gmail.com

Received: 2021-11-12

Accepted: 2021-12-06

Published: 2021-12-18

\section{ABSTRACT}

South Korea,'The Land of the Morning Calm', offers a different experience through a peaceful getaway to the Buddhist temple at Odaesan Mountain for historical tourism enthusiasts. Visiting the Odaesan national park offers various close-to-nature tourism experiences. The $11^{\text {th }}$ South Korea's national Park covers areas spread across Gangneung-si, Hongcheon-gun, and Pyeongchang-gun in Gangwon-do Province. The Park is a sanctuary for many native Korean animals and plants. Visitors may hike some of the peaks in the area, such as Birobong Peak, Durobong, Dongdaesan and Sogeumgang peaks. For those who would love to witness the country's national treasures, tourists may visit sangwonsa and woljeongsa temple in the vicinity. Woljeongsa and sangwonsa Temples are famous temples in Gangwon Province. It has been a museum for National Treasures of South Korea and cultural properties that recorded part of ancient history. Some of the relics are Dong Jong or Bronze Bell (National Treasure No. 36), Octagonal nine-story Stone Pagoda (National Treasure No. 48), Wooden Seated Child Manjushri of Sangwonsa Temple (National Treasure No. 221) and Documents of Sangwonsa Temple (National Treasure No. 292).

Keywords: Odaesan, Woljeongsa, Temple.

Cite This Article: Uropmabin, M.K. 2021. A Report Trip from Odaesan National Park \& Woljeongsa Temple. Bali Tourism Journal 5(3): 49-52. D0l: 10.36675/btj.v5i3.62

\section{INTRODUCTION}

South Korea, 'The Land of the Morning Calm', offers a different experience through a peaceful getaway to the Buddhist temple at Odaesan Mountain for historical tourism enthusiasts. Woljeongsa, the main Jogye Order's temple of Korean Buddhism, is located on the eastern slope of Odaesan mountain, in Pyeongchang County, Gangwon Province, South Korea. The temple has witnessed the history of political upheaval that shaped the country. This monument has undergone several restorations despite having experienced arson and destruction due to several wars. Today, the $7^{\text {th }}$-century temple becomes home to various historical relics. Some of them are pagodas and statues of Buddha. Besides being a museum for numerous relics of the past, the area around Woljeongsa Temple also offers breathtaking scenery and a peaceful atmosphere. As if to complement the perfection of historical tourism with spiritual nuances wrapped in harmony with nature. In Odaesan National Park, there is also the Sangwonsa temple. Sangwonsa is also often referred to as another hidden gem nestled among the hills and offering panoramic views of the many beautiful peaks of Pyeongchang.

\section{Native Wildlife Sanctuaries}

Before entering the sacred woljeongsa area, visitors will be greeted with a trail in the middle of the fir forest, part of the National Park. Situated in Gangwon-do central and eastern region, this Mount Odaesan area was designated a national park in February 1975. The $11^{\text {th }}$ South Korea's national Park covers areas spread across Gangneung-si, Hongcheon-gun, and Pyeongchang-gun in Gangwon-do Province with $303.929 \mathrm{~km}^{2}$. Odaesan National Park is divided into smaller sections: the Odaesan Section, Bangadari Bridge Section, Byeongnae-ri Section, Hwangbyeongsan Mountain Section, and Hongcheon-myeon Section, and Sogeumgang River Section with its nature profile of dense forest and gentle slopes. The highest peak of Odaesan is Birobong Peak, with 1563 meters' height. Most of the elevations in the Odaesan Mountains have flat land contours with gentle slopes, which is a common characteristic of mountains in the Korean peninsula. Other peaks include Dongdaesan $(1.434 \mathrm{~m})$, Durobong $(1.422 \mathrm{~m})$, Sangwangbong $(1.491 \mathrm{~m})$, and Horyeongbong $(1.561 \mathrm{~m})$. Meanwhile, To the east stands the peak of Noinbong $(1,338 \mathrm{~m})$, with the majestic Sogeumgang (Valley) extending beneath it.

As Korea's largest natural forest, the Odaesan area is home to many wild animals and species. ${ }^{1}$

There are 3,788 species of animals and plants living in Odaesan National Park. There are 1,040 plant species, including 30 species native to Korea. For animals, there are 28 species of mammals, 103 birds species, 13 amphibians species, 12 species of reptiles, 35 fish species, 1,976 insects species, 157 species of spiders, and 147 macroinvertebrates species. ${ }^{3}$

Odaesan National Park is divided by Baekdudaegan (the mountains known as the backbone of Korea) into Woljeongsa district and Sogeumgang district. There are many trails that visitors can choose from if they would like to hike some of the peaks in this area. From Sangwonsa Temple, Passing the Birobong Peak Trail will take visitors to the highest peak in Odaesan National Park, at the height of 


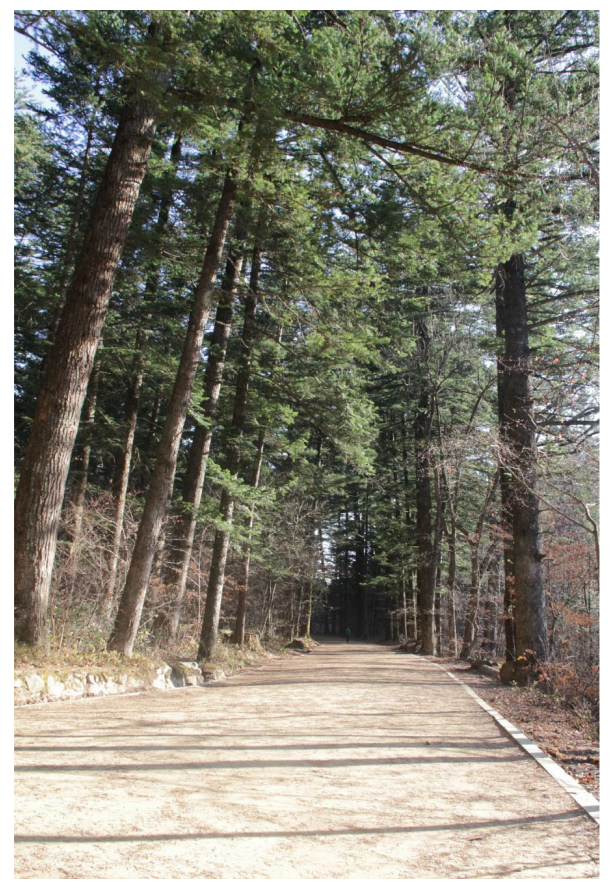

Figure 1. Trail in the middle of fir forest to explore Odaesan National Park. $^{2}$

$1,563 \mathrm{~m}$. Friendly hiking trails will take about 3-5 hours for a round trip. On the way, visitors will pass several peaks, namely Durobong, Dongdaesan and Sogeumgang. Visitors can also easily visit the Sangwonsa Temple, about 20 minutes by car from Woljeongsa. ${ }^{4}$

\section{Woljeongsa Temple}

Located at the entrance of Odaesan National Park, Woljeongsa Temple is one of the most famous temples in Gangwon Province. Gangwon province is the third most visited destination according to Korea National Tourism Survey 2015. Approximately about 2.5 hours driving to the northeast of Seoul. The history mentioned that a famous Vinaya Master from the Silla Dynasty named Jajang Yulsa built the woljeongsa temple in 643. Jajang Yulsa was a taeguksa or the Great Noble Priest of Shilla. ${ }^{6}$ At first, woljeongsa was just a simple hermitage. Today, the number of buildings on Korea's most important religious sites consists of more than 20 temples, 22 pagodas, and eight monasteries. Surrounded by hills, mountains, and hiking trails, it seems to support this place as a tourist destination that offers peace to anyone who visits it.

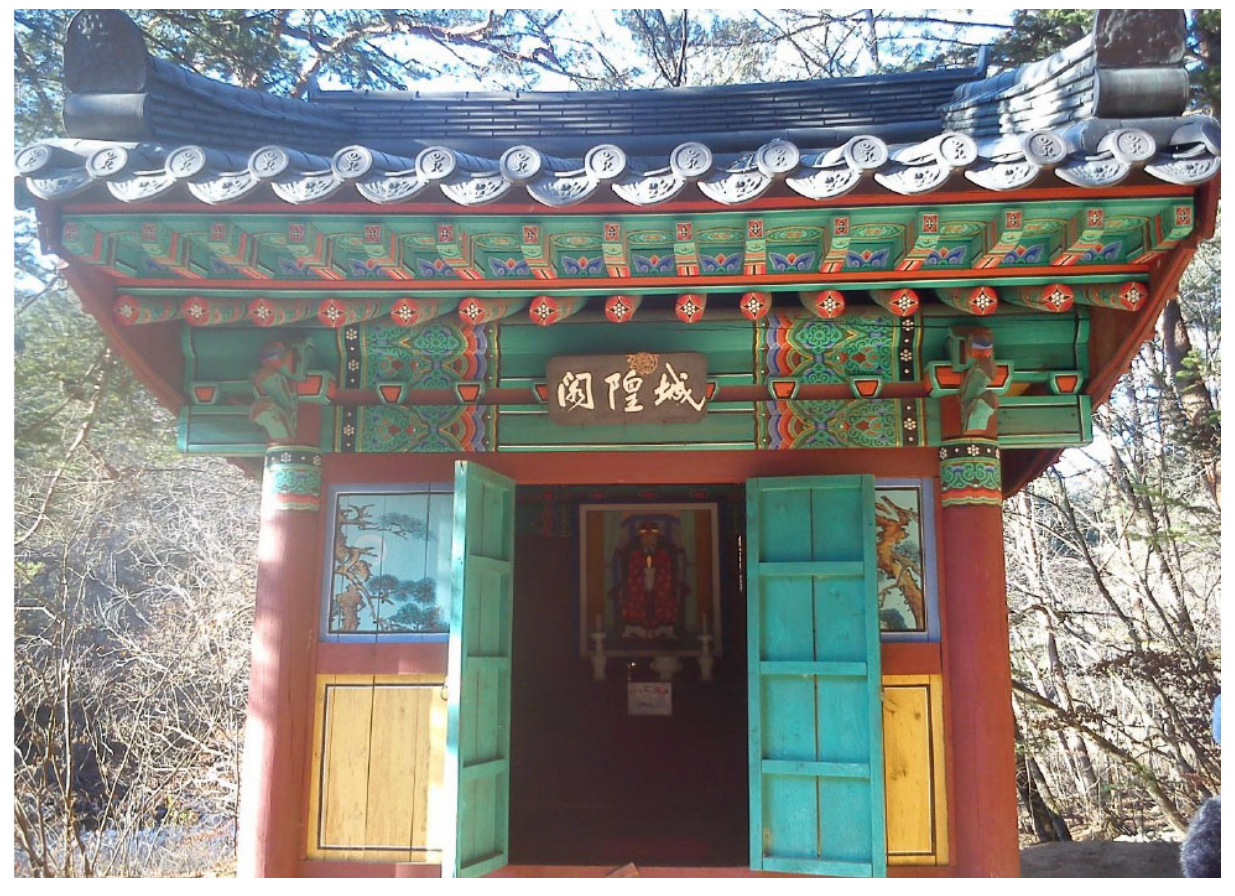

Figure 2. ${ }^{7}$ A Shrine in Odaesan

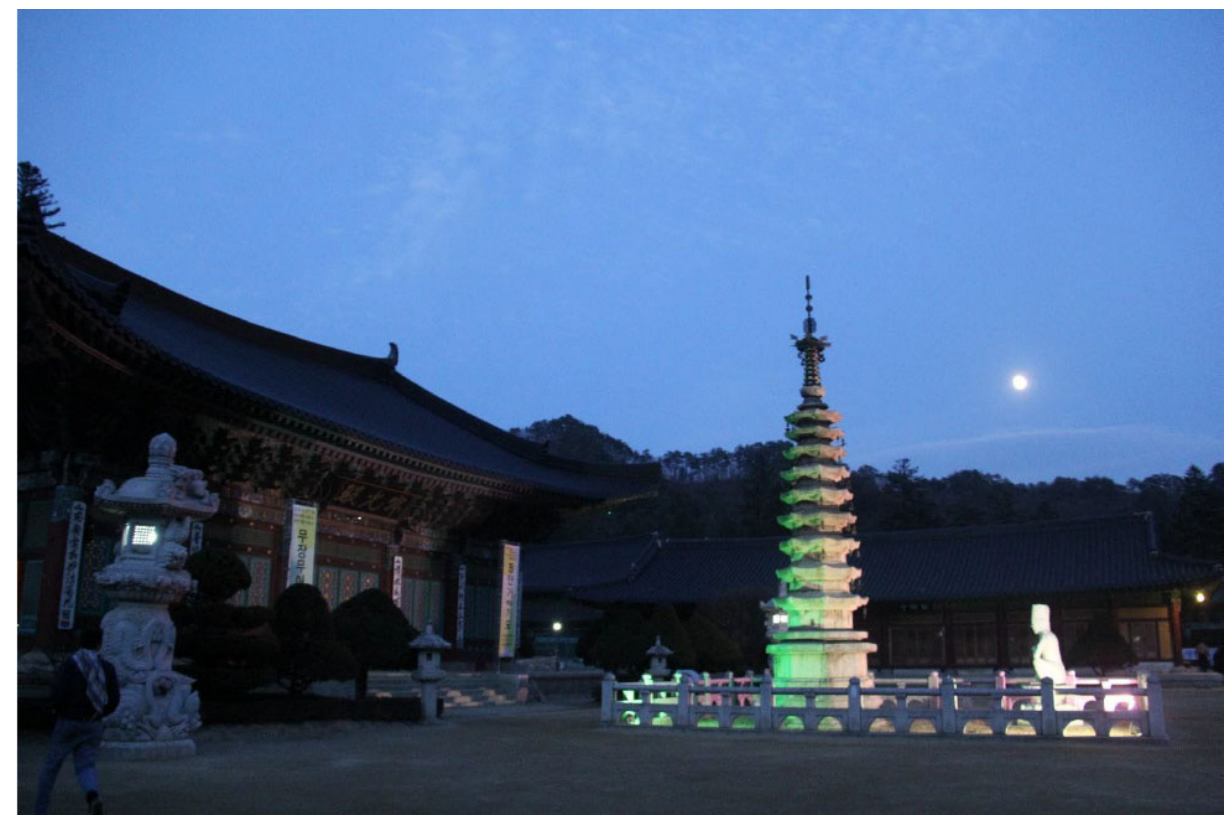

Figure 3. ${ }^{9}$ Octagonal nine-story Stone Pagoda (National Treasure No. 48).

According to the story, Jajang traveled to China to study and met the manifestation of the Bodhisattva Manjushri at Taihe Lake in Shanxi Province. Manjushri then gave Jajang some invaluable treasures such as a fragment of the original Sakyamuni Buddha's skull, a wooden begging-bowl, a monastic robe of Buddha, and 100 of the Buddha's sarira. Sarira is a pearl or crystal-like bead-shaped object that is purportedly found among the cremated ashes of Buddhist spiritual masters. After giving the treasures, then he told Jajang to return to Silla. The Bodhisattva said that he would meet Jajang again at Mount Odaesan, northeast of Gyeongju. Jajang 


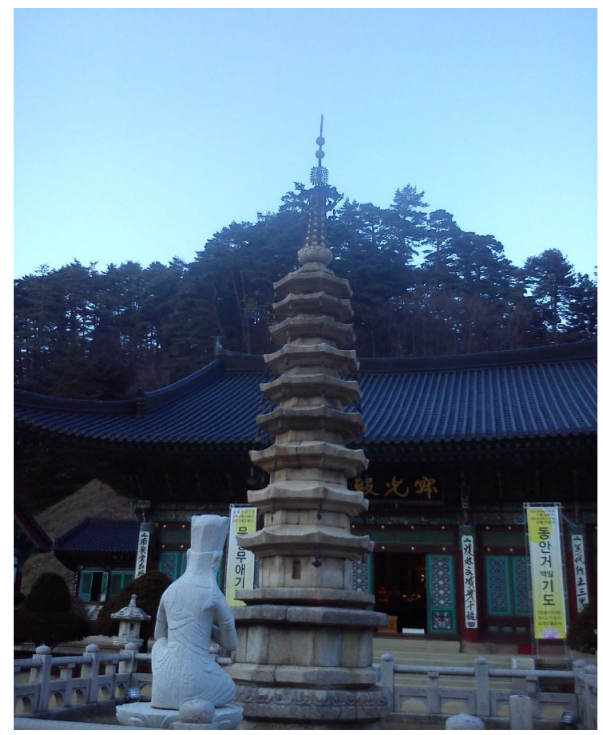

Figure 4. ${ }^{9}$ Octagonal nine-story Stone Pagoda (National Treasure No. 48).

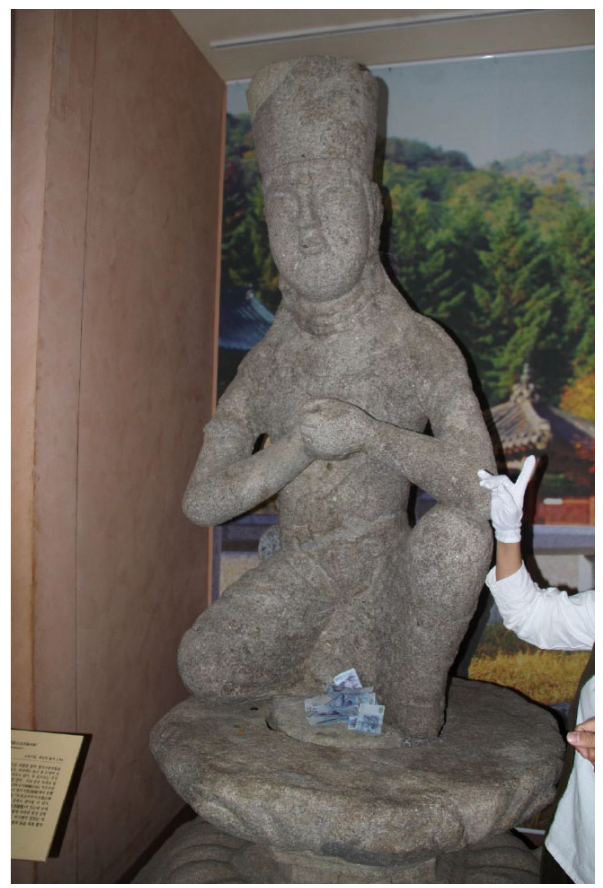

Figure 6. The Medicinal Buddha Statue ${ }^{10}$

went to the Odaesan region and built a temporary hut after arriving back in his home country. He prayed in this hut, wishing to meet Manjushri's manifestation again. However, his wishes were not fulfilled since heavy rain lasted for three days.

Besides woljeongsa, Jajang also built another hermitage on the area later known as sangwonsa temple. Sangwonsa

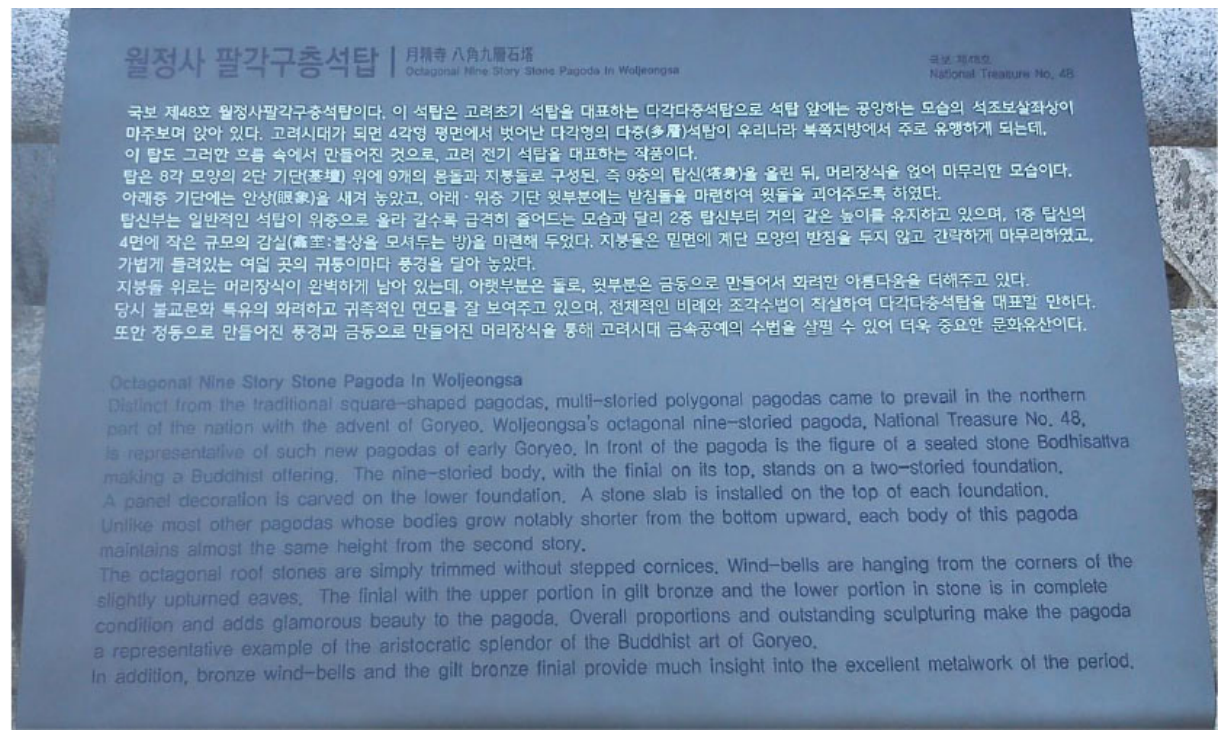

Figure 5. ${ }^{9}$ Octagonal nine-story Stone Pagoda (National Treasure No. 48).

Temple consists of a collection of ancient buildings and ornaments. It was built in the $12^{\text {th }}$ year Queen Seondeok of Silla, then rebuilt in 705. The temple burned down in 1946 but was restored in 1947. One of the important artifacts found there is the Sangwonsa Bronze Bell. This bronze bell is the oldest in Korea and is designated the 36th National Treasure of South Korea. In addition, there is also the Statue of the Son of Manjushri and the Gwangdaegeori building at the entrance of the temple. ${ }^{4}$

Sometime later, Sinhyo Geosa, a layman known as the reincarnated Young Educated Bodhisattva, resided on the site and developed his Buddhist practice. A student of National teacher Beomil Guksa, Ven. Sinui built a small hut in the same location as Jajang Yulsa's and lived there. After Sinui died, the place collapsed. This site eventually became a proper temple when Ven. Yuyeon of Sudasa Temple built a hermitage. However, In 1377, the abbey was burned to the ground, then Ven. I-il rebuilt it. In 1833 it was burned again, and in 1844 it was rebuilt by Yeongdam and Jeongam. During the Korean War in the 1950s, more than ten temple buildings, including Chilbul-bojeon, were burned down by friendly forces for strategic purposes. It was not until 1964 that Ven. Tanheo restarted the reconstruction, starting with the restoration of Jeokgwangjeon Hall. Due to the multiple arsons, this temple has undergone many reconstructions, and it turned the place into a particular temple complex that visitors may witness today.

\section{Home of National Treasures}

Visitors may find various cultural and religious artifacts, including four National Treasures of South Korea and five other treasures. Four national treasures of South Korea or gukbo are tangible items recognized by the Government. It might be a site, building, treasure, or artifact with an invaluable artistic design and cultural and historical value to the country. ${ }^{6}$

In the odaesan site temple, there are Dong Jong or Bronze Bell (National Treasure No. 36), Octagonal nine-story Stone Pagoda (National Treasure No. 48), Wooden Seated Child Manjushri of Sangwonsa Temple (National Treasure No. 221) and Documents of Sangwonsa Temple (National Treasure No. 292). The Woljeongsa's Pagoda is the only pagoda in South Korea that exhibits the characteristics of the Goguryeo Kingdom (37 BC-AD 668). The shrine often is called Sari-pagoda (relic pagoda), believed to have been built in the $10^{\text {th }}$ century. This multi-angle stone pagoda stood 15.2 meters/50 feet high and represented the popular multi-story pagoda during the Goryo Period, especially in the northern regions of Korea. However, its currently 
exposed rock base is a new construction since the original base is beneath the surface. A new flat stone base has been laid on top of the original with lotus flowersengraved and other ornaments.

Pillars are carefully carved in each corner of the top surface of the stone. The first level shape and door frame drawing on all the sides of the stone body and the flat roof stones represent the Goryeo Period. The nine floors' roof structure and stone body make this pagoda feel stable. The thin body, curved corners, door frames on the lower body and variations in the octagonal shape illustrate the unique and aristocratic characteristics of the Buddhist culture of the Goryeo era. Then, a beautiful SeatedBodhisattva Stone figure is in front of the pagoda. A unique relic and is only found in northern Gangwon-do, including Gangneung and Woljeongsa. Meanwhile, the bronze bell of Sangwonsa, a temple related to Woljeongsa, is the oldest temple bell ever produced in Korea. This bell came with an interesting legend. Its design offers extraordinary beauty in its shape and the inscriptions of celestial figures flying on the waist.

In addition, the shrine conserves seventeen "Real Cultural Heritage" items designated by Gangwon-do, six "Cultural Heritage Materials," one "Historic Site," one "Folklore Heritage" item, and one "Inherited Cultural Heritage" item. Furthermore, The most distinguished statue on the site is 1.8 meters tall Bodhisattva statue. It is believed to be the Medicinal Buddha. The figure was founded in the Diamond Pool in the southern temple area, and the statue was dedicated to an unknown figure. The statue's characteristics are wearing a crown, a long face, and its long hair slightly covering its ears. On his neck are three lines carved into a necklace. The elbow rests on the head of a boy. Due to its unusual model, the statue might have been carved in the $11^{\text {th }}$ century by artisans of a particular sect.

\section{CONCLUSIONS}

Visiting the Odaesan national park offers various close-to-nature tourism experiences. The $11^{\text {th }}$ South Korea's national Park covers areas spread across Gangneung-si, Hongcheon-gun, and Pyeongchang-gun in Gangwon-do Province. The Park is a sanctuary for many native Korean animals and plants. Visitors may hike some of the peaks in the area, such as Birobong Peak, Durobong, Dongdaesan and Sogeumgang peaks. For those who would love to witness the country's national treasures, tourists may visit sangwonsa and woljeongsa temple in the vicinity. Woljeongsa and sangwonsa Temples are famous temples in Gangwon Province. It has been a museum for National Treasures of South Korea and cultural properties that recorded part of ancient history. Some of the relics are Dong Jong or Bronze Bell (National Treasure No. 36), Octagonal nine-story Stone Pagoda (National Treasure No. 48), Wooden Seated Child Manjushri of Sangwonsa Temple (National Treasure
No. 221) and Documents of Sangwonsa Temple (National Treasure No. 292).

\section{REFERENCES}

1. Odaesan National Park (오대산국립공원). Visit Korea[dot]or[dot]kr. 2021. Available at URL: https://english.visitkorea.or.kr/enu/ATR/ SI_EN_3_1_1_1.jsp?cid=264215

2. Image of Fir Forest Trail. 2014. Private Collection

3. National Parks of Korea. Korea National Park Service. 2021. Available at URL: https://english. knps.or.kr/Knp/Odaesan/Intro/Introduction. aspx? MenuNum $=1 \&$ Submenu $=\mathrm{Npp}$

4. Woljeongsa Temple Guide: Everything You Need to Know. beyondthebay[dot]co. 2021. Available at URL: https://www.beyondthebay. co/southkorea/woljeongsa-temple

5. 2015 Natinal Travel Survey Report. visitkorea[dot]co[dot]kr. 2015. Available at URL: https://kto.visitkorea.or.kr/viewer/view. kto?id=46517\&type $=$ bd

6. DA Mason. Tongdo Temple - Master Ja Jang's Mysterious Buddha-Jewel Monastery. Korean Times. 2010. Available at URL: http://www.koreatimes.co.kr/www/news/ art/2010/04/135_62578.html

7. Image of The Shrine. 2014. Private Collection

8. Jaegwang Kang. [Encyclopedia of Korean National Culture] Performance and future development direction of the revision and enhancement project (2007-2017). Korean Dictionary , 2019, 34: 7-37.

9. Woljeongsa Octagonal nine-story Stone Pagoda. 2014. Private Collection

10. The Medicinal Buddha Statue. 2014. Private Collection

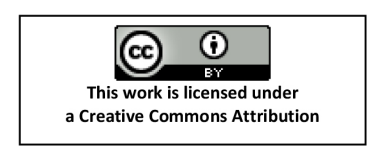

